\title{
Otomasi Greenhouse Berbasis Mikrokomputer RASPBERRY PI
}

\author{
Adi Fajaryanto Cobantoro ${ }^{\text {, Mohammad Bhanu Setyawan², Miftahudin Agung Budi Wibowo }}{ }^{3}$ \\ Universitas Muhammadiyah Ponorogo \\ 1adifajaryanto@gmail.com, ${ }^{2}$ bhanu@umpo.ac.id, ${ }^{3}$ miftahudin341@gmail.com
}

\begin{abstract}
ABSTRAK. Masuknya era revolusi industri, banyak terjadi antropogenik. Salah satu penyebab dari ketidakseimbangan ekologis yaitu minimnya penghijauan di lingkungan perkotaan. Kondisi lingkungan merupakan hal utama tercapainya hasil produksi. Faktor utama yang mempengaruhi tumbuh kembang tanaman adalah suhu dan kelembapan, dalam hal ini untuk mencapai suhu dan kelembapan yang diinginkan sangatlah sulit serta sulit dikendalikan sesuai dengan kebutuhan. Seakan suhu serta kelembapan tersebut membatasi produksi pertanian. Dari permasalahan yang ada maka dapat membangun prototype greenhouse bisa mengontrol suhu dan kelembapan secara otomatis sesuai kondisi sebenarnya pada tanaman. Untuk mencapai kondisi tersebut menggunakan sistem kontrol yang mengendalikan suhu dan kelembapan secara otomatis. Sistem bekerja sesuai nilai yang telah ditentukan kemudian nilai dibandingkan dengan sensor DHT22 untuk mengukur kelembapan udara dan YL-69 sebagai pengontrol kelembapan tanah dan sebagai pengontrol penyiraman tanaman secara otomatis. Pengujian prototype dilakukan menggunakan sebuah komputer dan mikrokontroler rassperry pi dengan cara menyambungkan kabel UTP ke raspberry pi ke laptop dengan koneksi sharing internet. Prototype bisa berjalan dan dapat dikontrol melalui telegram.
\end{abstract}

Kata Kunci: Greenhouse, Mikrokontroler Raspberry pi, DHT22, YL-69

\begin{abstract}
The entry of the industrial revolution era, many occur anthropogenic. One of the causes of ecological imbalances is the lack of reforestation in urban environments. Environmental conditions are the main thing to achieve production. The main factors that influence plant growth and development are temperature and humidity, in this case to reach the desired temperature and humidity is very difficult and difficult to control as needed. As if the temperature and humidity limit agricultural production. From the existing problems, building a greenhouse prototype can automatically control temperature and humidity according to the actual conditions in the plant. To achieve this condition use a control system that controls temperature and humidity automatically. The system works according to the value that has been determined then the value compared with the DHT22 sensor to measure air humidity and YL-69 as a controller of soil moisture and as a controller for watering plants automatically. The prototype testing was done using a computer and raspberry pi microcontroller by connecting the UTP cable to the raspberry pi to the laptop with an internet sharing connection. The prototype can run and can be controlled by telegram.
\end{abstract}

Keywords: Greenhouse,Raspberry pi, DHT22, YL-69, IoT

\section{PENDAHULUAN}

Masuknya era revolusi industri, memicu terjadinya antropogenik. Antropogenik merupakan aktifitas manusia yang memproduksi gas rumah kaca(Kahrahman, 2019). Aktifitas tersebut antara lain transportasi kendaraan bermesin, pembakaran sampah, rumah tangga dan industri. Hal ini disebabkan karena pertumbuhan jumlah populasi manusia yang begitu cepat sehingga saat ini kotakota besar sudah penuh sesak karena pengaruh urbanisasi. Tingginya populasi manusia berarti mempercepat konsumsi sumber daya alam, yang pada akhirnya akan menyebabkan ketidakseimbangan ekologis (Saaty \& Sagir, 2015).

Salah satu penyebab dari ketidak seimbangan ekologis yaitu minimnya penghijauan di lingkungan perkotaan. Hal ini dapat menimbulkan naiknya potensi pencemaran udara di kota besar. Kota Jakarta dan Hanoi merupakan dua kota yang menduduki peringkat atas yang paling tercemar (Indonesia, 2018). Menurunnya ruang terbuka hijau di kota besar menambah buruk kualitas udara di kota besar.

Untuk mengurangi efek pencemaran udara, saat ini sudah menjadi tren untuk menanam buah dan sayuran di rumah masing-masing melalui metode greenhouse. Greenhouse atau rumah kaca adalah bangunan yang terbuat dari plastik atau kaca yang tebal yang berfungsi untuk memanipulasi kondisi lingkungan mengurangi hama serta mempermudah petani memelihara tanaman 
(Rahmawati, 2019). Namun pada implementasinya tidak berjalan lancer, hal ini dikarenakan tidak ada waktu untuk merawat tanaman yang ada pada greenhouse. Sehingga diperlukan sebuah rekayasa perangkat lunak berdasar IoT (Internet of Things) yang dapat mengatur secara otomatis proses penyiraman dan suhu.

IoT merupakan salah satu teknologi canggih yang saat ini berkembang dan akan menjadi trend kedepannya. Teknologi ini berpotensi membawa dampak ekonomi menghasilkan keuntungan dari $\$ 2,7$ sampai $\$ 6,2$ pada tahun 2025 (Wu \& Yan, 2015). Artinya IoT juga akan menjadi bagian dari pengembangan teknologi pertanian yang menjadi fokus dunia dalam mengatasi keterbatasan lahan pertanian di tengah ketidakpastian iklim yang sering berubah karena pencemaran lingkungan.

Pada artikel ini ditawarkan sebuah purwarupa Mini Smart Green House yang bisa menjadi solusi terhadap warga ibukota yang ingin memperbaiki kualitas udara di dalam rumah dan menanam sayur serta buah namun masih dapat menjalankan rutinitas pekerjaan sehari-hari. Otomasi Greenhouse terdiri dari Raspberry Pi sebagai computer server, sensor DHT 22 dan YL-69.

Raspberry Pi merupakan komputer mini yang dapat digunakan produk yang dapat disesuaikan untuk kepentingan IoT (Internet of Things) (Cobantoro, 2017; Masykur et al., 2016; A. Prasetyo, Teknik, Studi, Informatika, \& Ponorogo, 2016). Sensor DHT22 digunakan untuk mengambil data suhu dan kelembapan udara, sedangkan sensor YL-69 berfungsi untuk mendeteksi kelembapan tanah dan mendistribusikan air. Sehingga tanaman akan terkontrol dan pertumbuhan tanaman akan lebih maksimal dibandingkan dengan tanaman yang dibudidayakan di luar greenhouse.

\section{TINJAUAN PUSTAKA}

\section{A. Green House}

Green house pada prinsipnya adalah sebuah bangunan yang terbuat dari bahan plastic atau kaca yang sangat tebal dan menutupi seluruh permukaan bangunan dari atap sampai dinding dan juga dilengkapi dengan peralatan yang mengontrol kelembapan, distribusi dan pupuk. Green house sebuah bangunan dimana tanaman seperti sayur, buah dan tanaman pangan dapat dibudidayakan dengan iklim yang bisa diatur yang melindungi tanaman dari panas dan dingin berlebih, debu, hama, intesitas cahaya, suhu dan kelembapan sehingga hasil panen bisa maksimal(Wardani, 2017).

B. Temparatur / Suhu

Pertumbuhan tanaman sangat dipengaruhi oleh temperature atau suhu, proses fotosintesis, transpirasi dan respirasi pada tanaman akan bekerja ma ksimal apabila suhu dan temperature di sekitarnya bekerja dengan baik sehingga menghasilkan pertumbuhan yang maksimal(Wardani, 2017).

C. Kelembapan udara dan Tanah

Kelembapan udara dan tanah sangat erat kaitannya dengan kadar air yang dibutuhkan oleh tumbuhan. Pertumbuhan tanaman akan semakin maksimal apabila semakin lembap. Kelembapan udara dan tanah sangat mempengaruhi proses transpirasi, fotosintesi, respirasi dan penyerapan air baik dari akar atau daun(Lomo, 2016).

D. Sensor Kelembapan Tanah

Sensor kelembapan adalah suatu alat ukur yang digunakan untuk membantu proses pengukuran kelembapan uap air yang terkandung dalam udara. Jenis-jenis sensor kelembaban diantaranya Cspacitive Sensors, Electrical conductivity Sensors, Thermal Conductivity Sensors, Optical Hygrometer, dan Oscillating Hygrometer(T. F. Prasetyo, Frastya, \& S, 2018).

E. Sensor Suhu

Sensor Suhu adalah suatu komponen yang bisa mengubah besaran panas menjadi besaran listrik sehingga bisa mendeteksi adanya perubahan suhu pada obyek tertentu. Sensor suhu melakukan pengukuran terhadap jumlah energy panas dan dingin yang dihasilkan oleh suatu obyek sehingga memungkinkan kita untuk mengetahui gejala perubahan-perubahan suhu tersebut dalam bentuk output analog maupun digital (Fadlilah \& Saniya, 2018). 


\section{HASIL DAN PEMBAHASAN}

Perancangan dan implementasi berikut ini menjelaskan terkait gambaran umum, perangkat keras, perangkat lunak dan implementasinya yang dijelaskan pada gambar 1 .

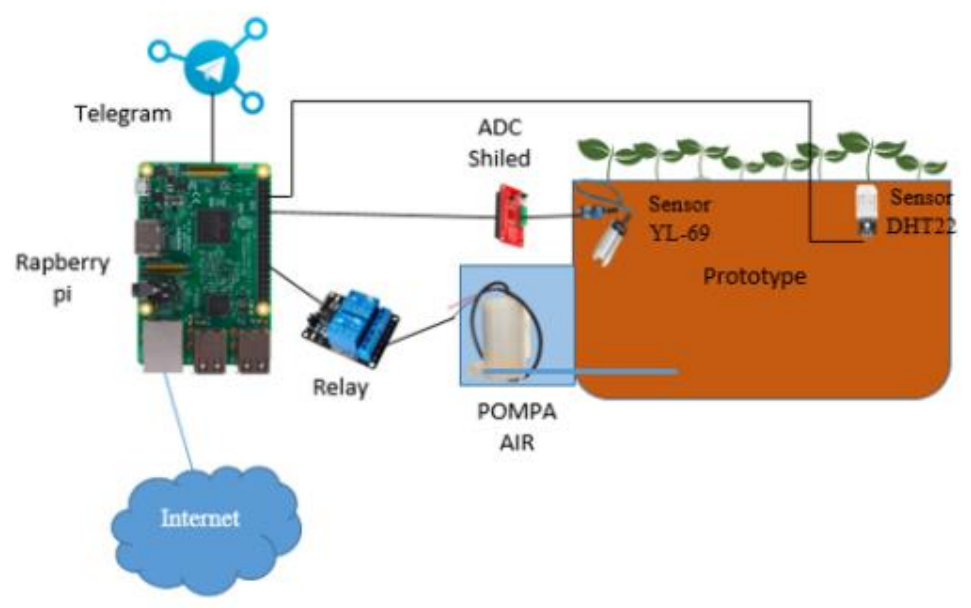

Gambar 1. Desain Smart Greenhouse

Dari gambar di atas terlihat model smart greenhouse pada ruangan greenhouse terdapat sensor DHT22 yang digunakan untuk mendeteksi suhu dan kelembapan pada ruangan greenhouse, sensor YL-69 digunakan untuk mendeteksi kelembapan tanah, nantinya sensor YL-69 juga akan berfungsi sebagai pengontrol pompa secara otomatis, Raspberry pi yang digunakan pada sisitem ini adalah Raspberry pi 3 model B, semua sensor disambungkan pada raspberry pi, ketika sensor DHT22 dihidupkan client bisa memonitor suhu dan kelembapan menggunakan telegram dengan mengetik perintah /temp pada chat telegram, kemudian raspberry mengambil data dari sensor DHT22 kemudian dikirim ke pesan singkat telegram. Selanjutnya sensor yl-69 untuk medeteksi apakah tanah kering atau lembab menggunakan nilai set point yang diperoleh sensor yl69. Ketika nilai melebihi nilai set point maka pompa akan menyala menandakan tanah kering, ketika dibawah nilai set point maka pompa akan mati, dan akan mengirimkan notif secara langsung ke telegram.

\section{A. Perancangan Perangkat Keras}

Perancangan perangkat keras terdiri dari raspberry Pi, sensor suhu dan kelembapan, sensor kelembapan tanah,relay, submarsible pump yang nantinya akan diimplementasikan ke dalam prototype sensor suhu, kelembapatan dan kelembapan tanah yang terhubung dengan pin GPIO pada raspberry pi, relay yang berfungsi untuk menyalakan dan mematikan pompa secara otomatis dan terhubung ke GPIO Raspberry pi. 


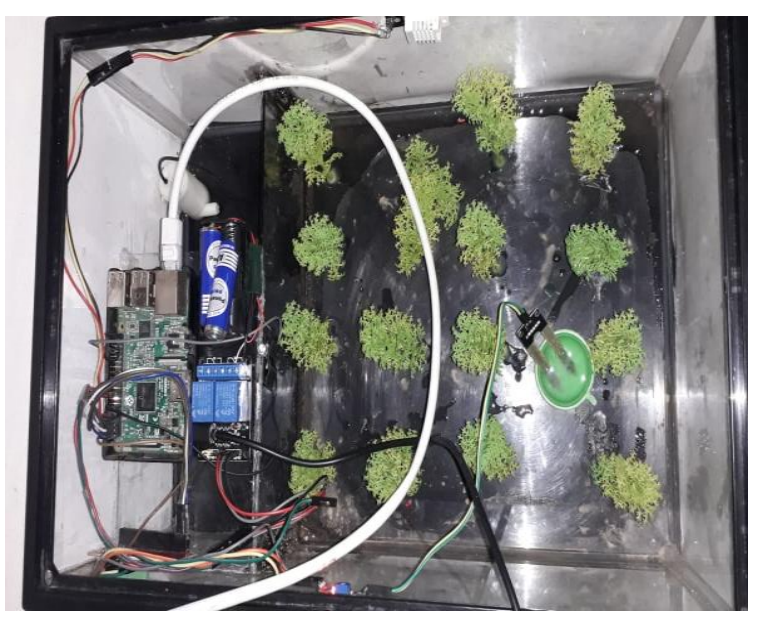

Gambar 2. Desain hardware

Terlihat pada gambar 2 peletakan Raspberry Pi di samping media tanam, kemudian sensor suhu dankelembapan berada di samping kanan media tanam dan sensor kelembapatan tanah berada di samping kiri media tanam, peletakan tersebut agar mudah mendeteksi masing-masing sensor.

Implementasi perangkat keras

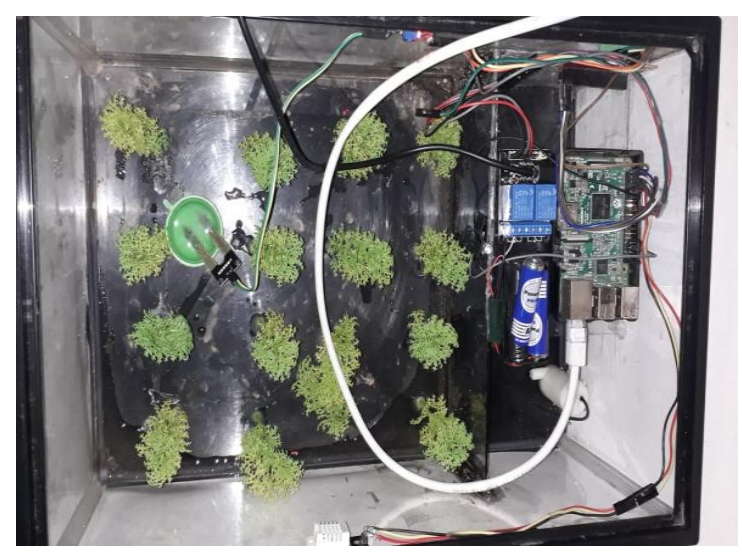

Gambar 3.Implementasiperangkatkeras

Implementasi perangkat keras menjelaskan proses pada hasil perancangan agar menjadikan sebuah sistem yang layak untuk digunakan, sistem ini menggunakan beberapa komponen yang memiliki fungsi yang berbeda yaitu Raspberry pi sebagai pusat kontrol sensor, DHT22 sevagai pendeteksi suhu da kelembapan, sensor YL-69 sebagai pendeteksi kelembapan tanah, relay 2 chanel sebagai sklar submarsible pump dan telegram sebagai penampil notifikasi (notif).

\section{B. Perancangan Perangkat Lunak}

Perancangan perangkat lunak yaitu perancangan pada raspberry pi sehingga sensor sensor dapat berjalan dengan baik sekaligus membaca nilai sensor yang digunakan dalam sisitem ini untuk mengirimkan ke telegram. 


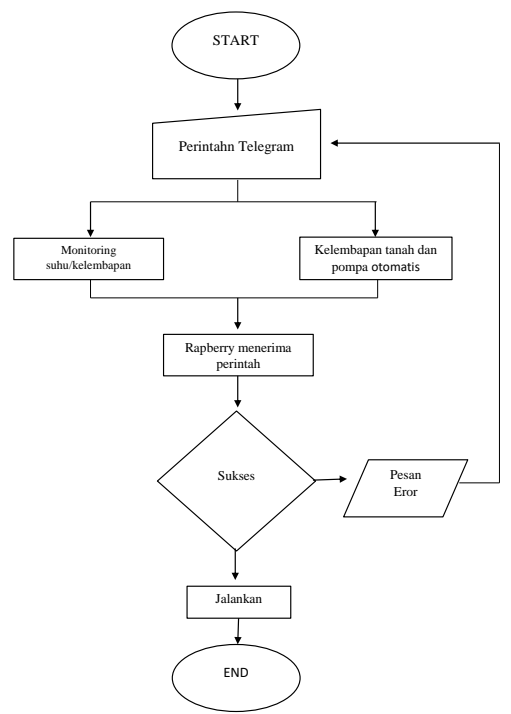

Gambar 4. Diagram Alir sistem

Diagram alir sistem dapat dilihat sensor DHT22 dan YL-69 mendapat perintah dari telegram selanjutnya raspberry pi mengambil data masing-masing sensor jika berhasil raspberry akan mengirim notif ke telegram jika gagal akan mendapat perintah eror.

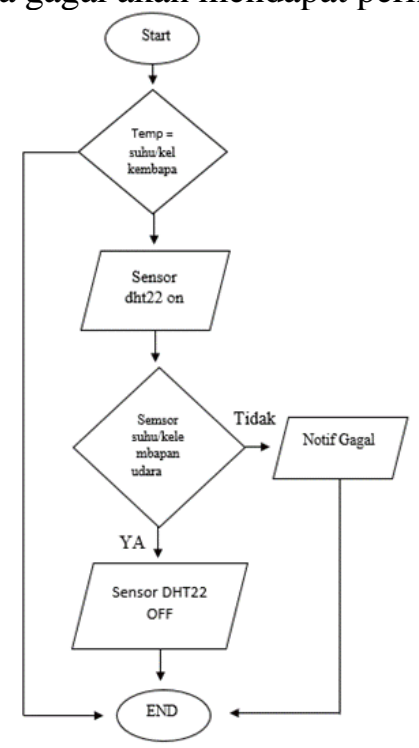

Gambar 5. Diagram alir sensor shu dan kelembapan udara

Pada tahapan ini (gambar 5) sensor akan mendeteksi suhu dan udara yang ada di ruangan greenhouse, dengan perintah "temp" maka raspberry akan menjalankan sensor DHT22 selanjutnya raspberry mengambil data sensor tersebut kemudian mengirimnya ke telegram dan memberikan pesan berupa berapa suhu dan kelembapan yang ada di greenhous secara real time. 


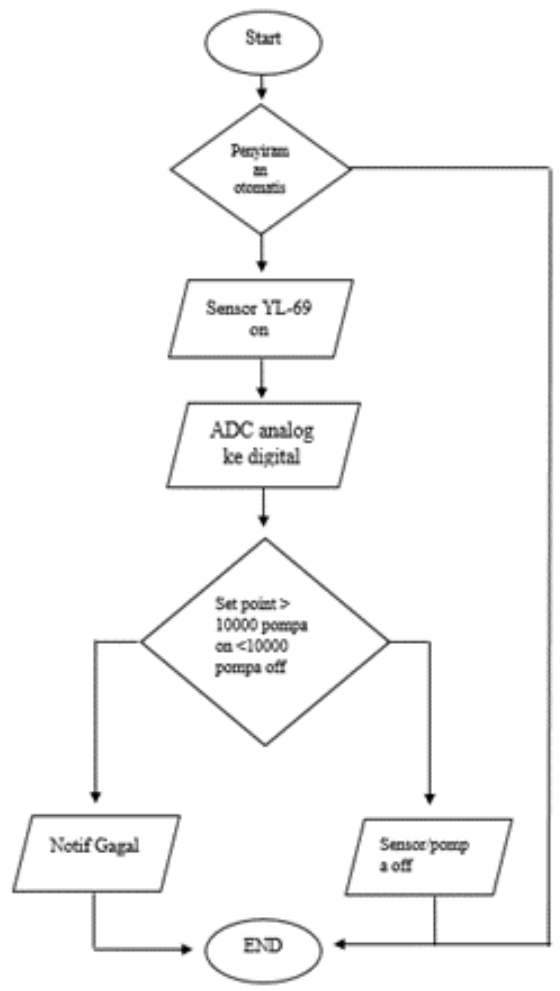

Gambar 6. Diagram alir sensor kelembapan tanah

Sensor Yl-69 soil moisture berfungsi sebagai pendeteksi media tanam masih ketersediaan air atau kering, Sebelumnya sensor YL-69 atau soil moisture sensor mempunyai output analog sedangkan raspberry tidak mmepunyai pin GPIO analog maka membutuhkan ADC shiled yang di rancang kusus untuk Mikrokontroler Raspberry PI unutk mengkonversi dari analog ke digital selanjutnya ADC shiled mengirim data ke Raspberry PI. Dengan nilai set point jika kelembapan $>10000$ pompa akan menyala menandakan kelembapan tanah sudah mencapai batas kering dengan notif "KADAR AIR TANAH MASIH TERPENUHI" jika $<10000$ maka pompa akan mati menandakan tanah sudah mendapatkan air. Kemudian notif tersebut dikirimkan ke user melalui telegram.

\section{C.Hasil Pengujian dan Kalibrasi}

Pada tahapan ini setelah semua perangkat sensor terhubung dengan Raspberry PI, tahapan selanjutnya melakuka pengujian dengan kendali telegram untuk tampilan awal dapat di lihat pada gambar di bawah ini: 


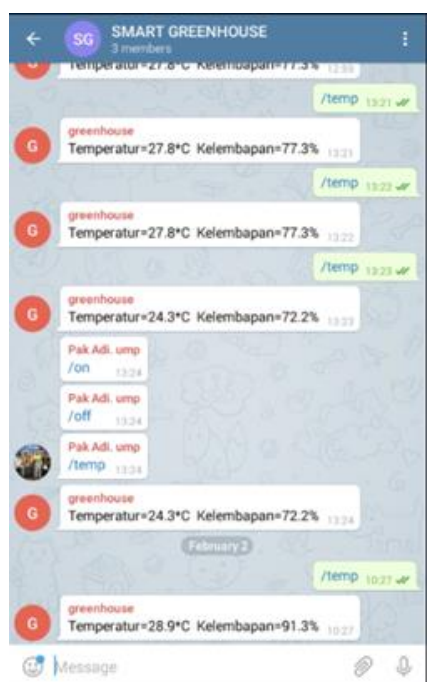

Gambar 7. Pengujian melalui telegram

Kemudian untuk mengecek ketersedian air pada tanah Greenhouse secara langsung dikirim ke telegram ketika tanah sudah mencapai ambang kering yang dilakukan pompa submarsible pump dapat dilihat pada gambar 8 dibawah ini

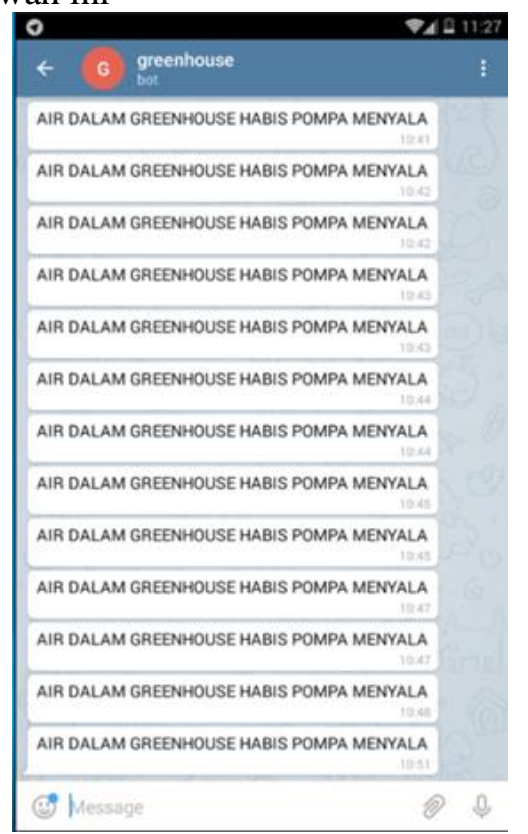

Gambar 8. Tampilan notif tanah kering

Selanjutnya menguji respon sensor saat mengirim notif ke telegram $<10000$ dengan Notif "AIR DALAM GREENHOUSE HABIS POMPA MENYALA" data tersebut diperoleh dari hasil konfersi dari ADC shiled yang telah merubah dari analog ke digital.

Berikut adalah tabel hasil analisis kalibarasi pada saat sensor menyala. 
Tabel 1. Pengujian kalibrasi sensor kelembapan tanah

\begin{tabular}{|c|c|c|c|}
\hline No & $\begin{array}{l}\text { Soil moisture } \\
\text { sensor yl-69 }\end{array}$ & PING telegram & Keterangan \\
\hline 1. & 10134 & $215 \mathrm{~m} / \mathrm{s}$ & TANAH MEMBUTUHKAN AIR \\
\hline 2. & 10134 & $215 \mathrm{~m} / \mathrm{s}$ & TANAH MEMBUTUHKAN AIR \\
\hline 3. & 10134 & $213 \mathrm{~m} / \mathrm{s}$ & TANAH MEMBUTUHKAN AIR \\
\hline 4. & 10134 & $213 \mathrm{~m} / \mathrm{s}$ & TANAH MEMBUTUHKAN AIR \\
\hline 5. & 10069 & $213 \mathrm{~m} / \mathrm{s}$ & TANAH MEMBUTUHKAN AIR \\
\hline 6. & 10069 & $213 \mathrm{~m} / \mathrm{s}$ & TANAH MEMBUTUHKAN AIR \\
\hline 7. & 10069 & $212 \mathrm{~m} / \mathrm{s}$ & TANAH MEMBUTUHKAN AIR \\
\hline 8. & 10069 & $212 \mathrm{~m} / \mathrm{s}$ & TANAH MEMBUTUHKAN AIR \\
\hline 9. & 10069 & $212 \mathrm{~m} / \mathrm{s}$ & TANAH MEMBUTUHKAN AIR \\
\hline 10. & 10069 & $215 \mathrm{~m} / \mathrm{s}$ & TANAH MEMBUTUHKAN AIR \\
\hline 11. & 10039 & $215 \mathrm{~m} / \mathrm{s}$ & TANAH MEMBUTUHKAN AIR \\
\hline 12. & 10039 & $213 \mathrm{~m} / \mathrm{s}$ & TANAH MEMBUTUHKAN AIR \\
\hline 13. & 10039 & $213 \mathrm{~m} / \mathrm{s}$ & TANAH MEMBUTUHKAN AIR \\
\hline 14. & 10039 & $212 \mathrm{~m} / \mathrm{s}$ & TANAH MEMBUTUHKAN AIR \\
\hline 15. & 10039 & $215 \mathrm{~m} / \mathrm{s}$ & TANAH MEMBUTUHKAN AIR \\
\hline 16. & 10039 & $213 \mathrm{~m} / \mathrm{s}$ & TANAH MEMBUTUHKAN AIR \\
\hline 17. & 10039 & $213 \mathrm{~m} / \mathrm{s}$ & TANAH MEMBUTUHKAN AIR \\
\hline 18. & 10039 & $215 \mathrm{~m} / \mathrm{s}$ & TANAH MEMBUTUHKAN AIR \\
\hline 19. & 10039 & $215 \mathrm{~m} / \mathrm{s}$ & TANAH MEMBUTUHKAN AIR \\
\hline \multicolumn{4}{|c|}{ Jumlah rata-rata $213 \mathrm{~m} / \mathrm{s}$} \\
\hline
\end{tabular}

Tahapan menguji respon sensor saat mengirim notif ke telegram >10000 dengan Notif "AIR DALAM GREENHOUSE TERPENUHI” Berikut adalah tabel hasil analisis kalibrasi.

Tabel 2.Tampilan kalibrasi sensor kelembapan tanah

\begin{tabular}{|c|c|c|c|}
\hline No & $\begin{array}{l}\text { Soil moisture } \\
\text { sensor yl-69 }\end{array}$ & $\begin{array}{c}\text { PING } \\
\text { telegram }\end{array}$ & Keterangan \\
\hline 1. & 9220 & $258 \mathrm{~m} / \mathrm{s}$ & KADAR ATR TANAH MASTH TERPENUHI \\
\hline 2. & 9220 & $251 \mathrm{~m} / \mathrm{s}$ & KADAR AIR TANAH MASH TERPENUHI \\
\hline 3. & 9220 & $257 \mathrm{~m} / \mathrm{s}$ & KADAR ARR TANAH MASHH TERPENUHI \\
\hline 4. & 9220 & $259 \mathrm{~m} / \mathrm{s}$ & KADAR ARR TANAH MASIH TERPENUHI \\
\hline 5. & 9218 & $254 \mathrm{~m} / \mathrm{s}$ & KADAR ARR TANAHMASH TERPENUH \\
\hline 6. & 9218 & $264 \mathrm{~m} / \mathrm{s}$ & KADAR, ARR TANAH MASH TERPENUH \\
\hline 7. & 9218 & $250 \mathrm{~m} / \mathrm{s}$ & KADAR AIR TANAH MASH TERPENUHI \\
\hline 8. & 9218 & $259 \mathrm{~m} / \mathrm{s}$ & KADAR ARR TANAH MASAH TERPENUH \\
\hline 9. & 9220 & $272 \mathrm{~m} / \mathrm{s}$ & KADAR AIR TANAH MASHH TERPENUH \\
\hline 10. & 9220 & $267 \mathrm{~m} / \mathrm{s}$ & KADAR ARR TANAH MASH TERPENTH \\
\hline 11. & 9220 & $268 \mathrm{~m} / \mathrm{s}$ & KADAR AIR TANAH MASHH TERPENUHI \\
\hline 12. & 9220 & $263 \mathrm{~m} / \mathrm{s}$ & KADAR ARR TANAH MASRH TERPENUTH \\
\hline 13. & 9220 & $264 \mathrm{~m} / \mathrm{s}$ & KADAR AIR TANAH MASTH TERPENUH \\
\hline 14. & 9220 & $259 \mathrm{~m} / \mathrm{s}$ & RADAR ARR TANAH MASTH TERPENUH \\
\hline 15. & 9220 & $260 \mathrm{~m} / \mathrm{s}$ & KADAR ARR TANAH MASTH TERPENTH \\
\hline 16. & 9220 & $259 \mathrm{~m} / \mathrm{s}$ & KADAR AIR TANAH MASHH TERPENUH \\
\hline 17. & 9220 & $267 \mathrm{~m} / \mathrm{s}$ & KADAR ARR TANAH MASDH TERPENUI \\
\hline 18. & 9220 & $261 \mathrm{~m} / \mathrm{s}$ & KADAR AIR TANAH MASTH TERPENUHI \\
\hline 19. & 9220 & $264 \mathrm{~m} / \mathrm{s}$ & KADAR ARR TANAH MASZH TERPENUH \\
\hline \multicolumn{4}{|c|}{ Jumlah rata-rata $213 \mathrm{~m} / \mathrm{s}$} \\
\hline
\end{tabular}

Selanjutnya kalibrasi sensor suhu dan kelembapan ruangan greenhouse ditunjukan pada tabel 3 berikut. 
Tabel 3. Kalibrasi sensor suhu dan kelembapan udara

\begin{tabular}{lll}
\hline No & SENSOR DHT22 & PING telegram \\
\hline & & \\
1. & Temp $=28.0^{*} \mathrm{C}$ Kelem $=95.5 \%$ & $252 \mathrm{~m} / \mathrm{s}$ \\
2. & Temp $=28.0^{*} \mathrm{C}$ Kelem $=95.8 \%$ & $214 \mathrm{~m} / \mathrm{s}$ \\
3. & Temp $=28.0^{*} \mathrm{C}$ Kelem $=95.8 \%$ & $213 \mathrm{~m} / \mathrm{s}$ \\
4. & Temp $=28.1^{*} \mathrm{C}$ Kelem $=95.8 \%$ & $212 \mathrm{~m} / \mathrm{s}$ \\
5. & Temp $=28.1^{*} \mathrm{C}$ Kelem $=95.8 \%$ & $212 \mathrm{~m} / \mathrm{s}$ \\
6. & Temp $=28.1^{*} \mathrm{C}$ Kelem $=95.8 \%$ & $303 \mathrm{~m} / \mathrm{s}$ \\
7. & Temp $=28.1^{*} \mathrm{C}$ Kelem $=95.9 \%$ & $223 \mathrm{~m} / \mathrm{s}$ \\
8. & Temp $=28.1^{*} \mathrm{C}$ Kelem $=96.6 \%$ & $245 \mathrm{~m} / \mathrm{s}$ \\
9. & Temp $=28.1^{*} \mathrm{C}$ Kelem $=96.1 \%$ & $268 \mathrm{~m} / \mathrm{s}$ \\
10. & Temp $=28.1^{*} \mathrm{C}$ Kelem $=96.1 \%$ & $290 \mathrm{~m} / \mathrm{s}$ \\
& & \\
\hline
\end{tabular}

\section{KESIMPULAN DAN SARAN}

Berdasarkan hasil pengujian kalibrasi yang telah dilakukan, maka dapat diambil kesimpulan sebagai berikut.

1. Penelitian ini menggunakan prototype yang cara kerjanya secara otomatis, dan program yang dirancang berjalan dengan baik sesuai yang diharapkan seperti mengecek suhu dan kelembapan udara maupun pengairan secara otomatis.

2. Untuk mengendalikan program melalui pesan Telegram berjalan dengan lancer sesuai awal perancangan, pengiriman pesan tidak ada kendala walapun dikendalikan dalam jarak jauh.

3. Pengujian prototype dilakukan menggunakan sebuah computer dan mikrokontroler Raspberry PI dengan cara menyambungkan kabel UTP ke Raspberry PI ke laptop dengan koneksi sharing internet sehingga prototype bisa berjalan dan dapat dikontrol melalui Telegram.

\section{DAFTAR RUJUKAN}

Cobantoro, A. F. (2017). Rekayasa Web Proxy Pada Komputer Mikro Untuk Keamanan Anak Dalam Berinternet. In Seminar Nasional dan Gelar Produk 2017 (p. 171).

Fadlilah, U., \& Saniya, N. (2018). MONITORING SUHU KABEL TRAFO MELALUI TAMPILAN LCD DAN SMS. Emitor, 17(02), 1-8.

Indonesia, G. (2018). Greenpeace Media Briefing Data Terkini Kualitas Udara Kota-kota di Seluruh Dunia.

Kahrahman, S. (2019). Evaluating University Students ' Understanding of Atmospheric Environmental Issues Using a Three-Tier Diagnostic Test **. International Electronic Journal of Environmental Education, 9(1), 1-17.

Lomo, L. A. (2016). Smart Greenhouse Berbasis Mikrokontroler Arduino Mega 2650 Rev 3. Universitas Sanata Dharma.

Masykur, F., Prasetiyowati, F., Studi, P., Informatika, T., Ponorogo, U. M., \& Pi, R. (2016). Aplikasi Rumah Pintar ( Smart Home ) Pengendali Peralatan, 3(1), 51-58.

Prasetyo, A., Teknik, F., Studi, P., Informatika, T., \& Ponorogo, U. M. (2016). Rancang Bangun Database Dua Arah, 7(2), 769-774.

Prasetyo, T. F., Frastya, E. A., \& S, E. E. (2018). Sistem Pendeteksi Kesuburan Tanah Pada Desa 
Cihaur Kelompok Tani Bina Mandiri, 191-198.

Rahmawati, D. (2019). Pengujian Monitoring On-Line Rumah Kaca Cerdas Berbasis Android. Cyclotron, 2(1). https://doi.org/10.30651/cl.v2i1.2529

Saaty, T. L., \& Sagir, M. (2015). Choosing the best city of the future. Journal of Urban Management, 4(1), 3-23. https://doi.org/10.1016/j.jum.2015.06.003

Wardani, A. (2017). Purwarupa Perangkat IoT Untuk Smart Greenhouse Berbasis Mikrokontroler. Universitas Telkom.

Wu, G. Le, \& Yan, D. S. (2015). Parking Information Monitoring and Management System Based on Internet of Things Technology. Applied Mechanics and Materials, 738-739, 229-232. https://doi.org/10.4028/www.scientific.net/amm.738-739.229 